WellBeing International

WBI Studies Repository

1999

\title{
Behavioral Interactions and Conflict Among Domestic Dogs, Black-Tailed Prairie Dogs, and People in Boulder, Colorado
}

Marc Bekoff

University of Colorado

Robert W. Ickes

University of Colorado

Follow this and additional works at: https://www.wellbeingintlstudiesrepository.org/acwp_ena

Part of the Animal Studies Commons, Behavior and Ethology Commons, and the Comparative Psychology Commons

\section{Recommended Citation}

Bekoff, M., \& Ickes, R. W. (1999). Behavioral interactions and conflict among domestic dogs, black-tailed prairie dogs, and people in Boulder, Colorado. Anthrozoös, 12(2), 105-110.

This material is brought to you for free and open access by WellBeing International. It has been accepted for inclusion by an authorized administrator of the WBI Studies Repository. For more information, please contact wbisr-info@wellbeingintl.org.

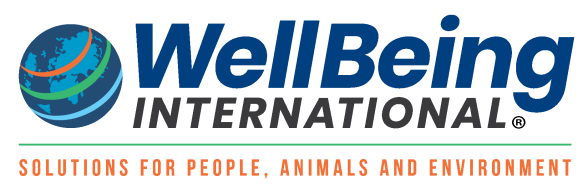




\title{
Behavioral Interactions and Conflict Among Domestic Dogs, Black-Tailed Prairie Dogs, and People in Boulder, Colorado
}

Marc Bekoff and Robert W. Ickes

University of Colorado

\begin{abstract}
$\underline{\text { ABSTRACT }}$
Interactions among domestic dogs (Canis familiaris), black-tailed prairie dogs (Cynomys ludovicianus), and people were studied at Dry Creek, Boulder, Colorado. Our objective was to develop a basic understanding of the nature of dog-prairie dog interactions in this recreational area, because this is an issue that has high visibility and over which there is conflict in Boulder: There are those who want dogs to run free regardless of their impact on the behavior and lives of prairie dogs and those who want to protect prairie dogs and have dogs restrained or go elsewhere. We found that dogs clearly influenced the behavior of prairie dogs, however, no prairie dogs were known to be caught or killed by any dog during the course of study. Prairie dogs disturbed by dogs were more alert (vigilant) and wary of dogs and played less than undisturbed individuals. However, disturbed prairie dogs were less wary of the presence of humans than undisturbed animals. People tried to stop dogs from harassing prairie dogs only $25 \%$ of the time. A survey showed that 58\% of people polled at Dry Creek (all dog owners) did not believe that prairie dogs should be protected even if dogs are a problem. Increased human responsibility would likely go a long way towards reducing existing conflict among people wanting to protect prairie dogs and those who do not. Boulder city officials have not yet incorporated our data into their immediate management plans. However, by identifying the nature of dog-prairie dog encounters and specific areas of conflict among people who side either with dogs or prairie dogs, in the future, proactive strategies grounded by empirical data can be developed and implemented so that the interests of all parties can be accommodated.
\end{abstract}

\section{INTRODUCTION}

World-wide there is growing interest in how human and non-human animals (hereafter animals) can best share what is becoming a limited resource, namely space that can be used by all parties for a variety of activities (see Knight and Gutzwiller 1995 for review). In Boulder, Colorado (USA) and other locales, among the numerous issues regarding land use is the concern that free-running domestic dogs (Canis familiaris) cause disturbance to wildlife and habitat. Yet, there are few detailed studies on relationships between dogs and wildlife (Miller 1994, Knight and Gutzwiller 1995, Bekoff and Meaney 1997, and references therein). In Boulder, dogs and prairie dogs share areas that are used for recreational purposes by people and their companion dogs. Conflict abounds because some people argue that dogs should be allowed to run free regardless of their impact on prairie dogs, whereas others maintain that prairie dogs should be protected and that dogs should be restrained or be taken elsewhere if they are to run free. There are no formal studies of which we are aware that focus on the nature of interactions between dogs and black-tailed prairie dogs (Cynomys ludovicianus), specifically avoidance shown by prairie dogs in 
response to intrusions and harassment by dogs. Two previous studies showed that prairie dogs in rural and undisturbed areas were more sensitive to human and other disturbances than were prairie dogs in urban areas (Adams, Lengas, and Bekoff 1987, Farrar et al. 1998).

Issues concerning the impact of dogs on habitat and wildlife, including prairie dogs, require more detailed attention. Dogs and prairie dogs interact frequently in various contexts, and there is a lot of interest in the management of prairie dog colonies in and around Boulder and also nationally because of the potential harm that dogs might bring to prairie dogs. Indeed, there is a lot of popular interest in prairie dogs (e.g. Dold 1998, Long 1998; Reading, Miller and Kellert 1999), and there is a serious move to have black-tailed prairie dogs listed as "threatened" under the Endangered Species Act because only about 1\% of their original number occupy about $1 \%$ of their historic range. Prairie dogs are also vital for the survival of numerous (perhaps as many as 200) species associated with prairie dog towns, including endangered black-footed ferrets (Mustela nigripes; Miller, Reading, and Forrest 1996), and some believe they are a keystone species (Davitt et al. 1996; but see Stapp 1998). If listed, prairie dogs would be protected from being harmed by poisons, recreational hunters, bulldozer scoops, or unrelenting human sprawl.

In this study we focused on interactions between free-running domestic dogs, black-tailed prairie dogs, and people at Dry Creek, an area designated by the city of Boulder as a Habitat Conservation Area in which attempts are made to maintain natural faunal and floral biodiversity and natural shifts in animal use and vegetation dominance. Observations were also made at a control area where there was little human and no dog use. Our general hypothesis was that prairie dogs who are less disturbed by humans will be more wary than prairie dogs who are greatly intruded on by humans. This hypothesis stemmed from earlier work in which it was shown that prairie dogs in rural and undisturbed areas were more sensitive to human and other disturbances than were prairie dogs in urban areas (Adams et al. 1987, Farrar et al. 1998). We also predicted that prairie dogs who are heavily disturbed, when compared to prairie dogs who are less disturbed, would show greater disruption of normal activity patterns than less disturbed prairie dogs. Thus, disturbed prairie dogs might be more stressed than undisturbed individuals, and they might rest, forage, or socially interact less than undisturbed animals.

\section{METHODS}

Data were collected by direct observation of dogs, prairie dogs, and people during September, October, and November 1998, at Dry Creek, a recreational area in East Boulder. The prairie dog colony extends over approximately 14 acres. Trail corridors fragment prairie dog habitat. Observations were conducted by 12 researchers for approximately 250 hours, and about 150 different dogs were observed. Observations were conducted throughout daylight hours as the use of Dry Creek varies throughout the day. Data were either recorded by hand or read into an audio cassette and later transcribed. Time was measured on hand-held stopwatches and distances were determined using measuring tapes or estimated using natural landmarks between which distances were known. Different areas at Dry Creek were sampled randomly to minimize the likelihood of our seeing the same people, dogs, and prairie dogs from day-to-day. The responses of prairie dogs to humans at Dry Creek and at a control area (the Marshall Area) about $1 \mathrm{~km}$ southeast of Dry Creek where there was little human and no dog use, were also studied to determine if prairie dogs at Dry Creek behaved similarly to other populations of disturbed animals (Adams et al 1987, Farrar et al. 1998).

We used focal animal sampling (Altmann 1974) on all but one occasion, when one- zero sampling was used (see below). Observers selected a focal $\operatorname{dog}(\mathrm{s})$ and followed him or her from the time they arrived at Dry Creek and as they roamed about. At the same time, a focal prairie dog(s) was selected in the vicinity of the dog and its behavior was recorded before, during, and after an encounter with the dog(s). We attempted to select the prairie $\operatorname{dog}(\mathrm{s})$ nearest to the $\operatorname{dog}(\mathrm{s})$ as the focal animal(s). The focal dog was 
observed to see if he or she ignored or approached prairie dogs or prairie dog burrows, and the response of focal prairie dogs to this sort of disturbance was also noted. We also recorded whether the dog walked near or toward a burrow, stalked a prairie dog, ran toward a burrow before or after a prairie dog retreated, chased a prairie dog, or tried to extract a concealed animal. The behavior of people (with and without companion dogs) was also observed to see if they tried to stop dogs from harassing prairie dogs.

Frequency data were pooled for all observation periods and analyzed using proportions tests (Bruning and Kintz 1977, p. 222ff) which generate the $z$ statistic. We used $p<0.05$ (two-tailed test; $z_{\text {crit }}>1.96$ ) to indicate significant differences between two proportions.

\section{Prairie Dog-Human Interactions}

\section{Behavioral Responses to Disturbance}

In this part of our study we used measures that have been used in the past concerning the responses of prairie dogs to the approach of humans (Adams et al. 1987, Farrar et al. 1998). We were only concerned with physical intrusions, not the influence of olfactory or auditory infringements. The following behavioral measures were recorded:

a) Bark distance - distance between focal person and focal prairie dog when the prairie dog emits the initial warning signal and retreats to its burrow entrance;

b) Concealment distance - distance between focal person and the burrow when the focal prairie dog conceals itself in the burrow;

c) Sequence time - time the individual takes to perform the avoidance sequence of running to the burrow, pausing at the burrow entrance, flattening down inside the lip of the burrow, tail-wagging, barking, and concealing itself underground;

d) Concealment time - time from the moment that all individuals in the group conceal themselves until one reappears above ground.

Observations for concealment time at the control area were terminated at 600 sec because no prairie dogs reappeared above ground after disturbance within this time period.

We also recorded the time allotted to various behaviors by prairie dogs at Dry Creek during periods when they were relatively free of intrusions by dogs and when they were intruded on more heavily. Behavior patterns observed included being alert or vigilant (scanning for dogs while standing on hindlegs or lying down; no other terrestrial predators were present during observations and on only about five occasions were birds of prey observed) and playing (details on these and other behavior patterns performed by black-tailed prairie dogs are presented in Hoogland 1995).

In addition to information concerning dog-prairie dog interactions, we observed some general patterns of dog behavior, including how frequently they left the main trail and how far they went off trail.

\section{Prairie Dog-Human Interactions}

The response of prairie dogs to humans at Dry Creek and at the control area was studied to determine if prairie dogs at Dry Creek behaved similarly to other populations of disturbed animals.

\section{Human Attitudes}

We also administered a questionnaire that was slightly modified (to include questions about prairie dogdog interactions) from the one used in a previous study of dog-people interactions in Boulder (see Bekoff and Meaney 1997, Appendix A; available from MB). 


\section{RESULTS}

\section{Number, Size, and Movement Patterns of Dogs}

It was difficult to estimate the total number of different dogs observed during the course of study because numerous dogs frequented Dry Creek and because different observers did not have detailed information on visitation patterns, especially visits by unnamed dogs or those who looked alike. For example, there were numerous golden retrievers and medium-large dogs who could not be reliably identified over time. However, it was reasonable to conclude that at least 150 different individuals were observed. We estimated that about $70 \%$ of dogs visiting Dry Creek were "large" (> about $25 \mathrm{~kg}$ ). About $68 \%$ of all dogs traveled more than $5 \mathrm{~m}$ off the main trails. On eleven occasions dogs were lured off trail by humans throwing frisbees.

\section{Dogs and Prairie Dogs}

About $60 \%$ of all visiting dogs barked at prairie dogs, ran towards burrows, chased prairie dogs, or chased and attempted to extract concealed individuals. Some dogs were repeated nuisances, while others never disturbed prairie dogs. A detailed analysis of the behavior of 56 dogs for whom we could collect reliable information from the beginning to the end of an interaction showed that eight (14.3\%) barked at prairie dogs from a distance, 18 (32.1\%) ran toward a burrow(s), 18 (32.1\%) chased prairie dogs, and $12(21.4 \%)$ chased and attempted to extract a concealed prairie dog from its burrow. No prairie dogs were known to be caught or killed by any dog during the course of this study.

All observers independently agreed that large dogs disturbed prairie dogs more than smaller dogs. Prairie dogs barked at and fled from large dogs sooner (when dogs were about $11 \mathrm{~m}$ away) than small dogs (dogs were about $8.5 \mathrm{~m}$ away). How the size of intruding dogs influences the behavior of prairie dogs needs further analysis.

Prairie dogs disturbed by dogs were alert more often and played less often than undisturbed individuals. They commonly flicked their tails while scanning for intruders. Using one-zero sampling, we found that in 24 observation sessions, alertness was observed in $63 \%$ of the sessions and play was observed in $38 \%$ of the sessions during high intrusion by dogs ( $>60 \%$ of dogs disturbed prairie dogs). When intrusion was low ( $<15 \%$ of dogs disturbed prairie dogs), alertness was observed in $33 \%$ of the observation sessions and play was observed in $50 \%$ of them. The proportion of periods during which alertness and play were observed were significantly different when compared between periods of high and low intrusion (proportions test, $p<0.05$ ).

\section{Prairie Dogs and People}

Prairie dogs at Dry Creek were less wary of humans than prairie dogs at the control area where there was little human and no dog traffic. It was difficult to gather data on complete sequences (from barking to concealment) of prairie dog responses to human intrusion, but for the 16 sequences for which we did, we found that prairie dogs showed statistically significant differences in behavior between Dry Creek and the control site (MANOVA, Wilks' Lambda $=0.189$, Exact $F_{(5,10)}=8.56, p=0.002$ ). Prairie dogs at Dry Creek barked at a significantly shorter distance than animals at the control site [means $=74 \pm 17 \mathrm{~m}(\mathrm{sd})$ ] and $12 \pm 12 \mathrm{~m}$, respectively; $F_{(1,14)}=41.9, p<0.0001$; Figure 1), concealed themselves at a significantly shorter distance $\left(16 \pm 9 \mathrm{~m}, 60 \pm 20 \mathrm{~m}\right.$, respectively; $F_{(1,14)}=21.47, p=0.0004$; Figure 2$)$, and showed significantly shorter concealment times (334 $\pm 237 \mathrm{sec}, 600 \pm$ Osec, respectively; $F_{(1.14)}=15.15, p=0.0016$; Figure 3 ). There was no difference in total sequence time for prairie dogs at Dry Creek and at the control site (83 \pm 60 sec, $117 \pm 76 \mathrm{sec}$, respectively; $\left.F_{(1,14)}=0.814, p=0.382\right)$. 
A separate analysis of these four measures from a larger data set $(n=60)$ in which we could not record entire sequences showed the same results.

People tried to stop dogs from harassing prairie dogs only $25 \%$ of the time. Usually (about $90 \%$ of the time) people called their dogs but did not go after them. Once off trail most dogs chased prairie dogs.

Figure 1. Mean bark distances (and 95\% confidence intervals) for prairie dogs' responses to humans at the control site ("undisturbed") and at Dry Creek ("disturbed").

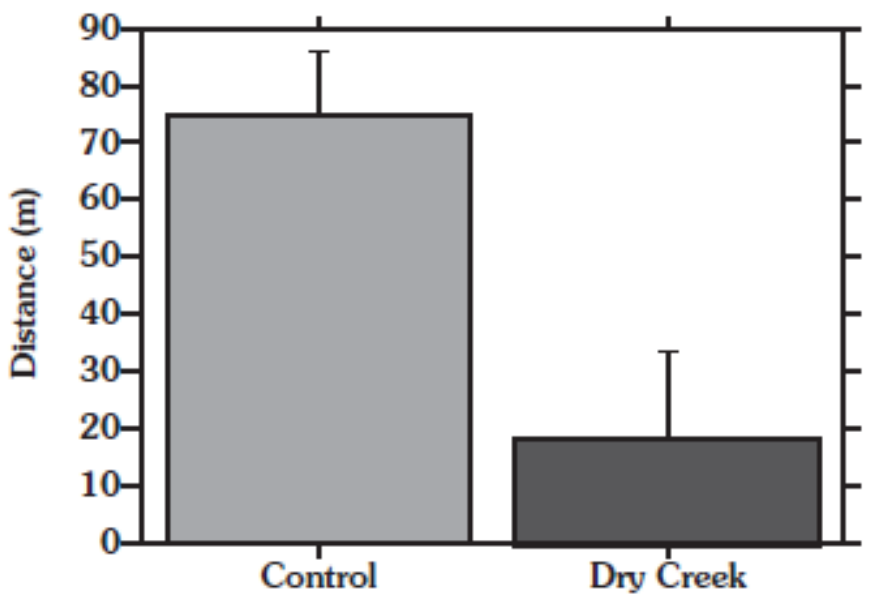

BARK DISTANCE

Figure 2. Mean concealment distances (and 95\% confidence intervals) for prairie dogs' responses to humans at the control site ("undisturbed") and at Dry Creek ("disturbed").

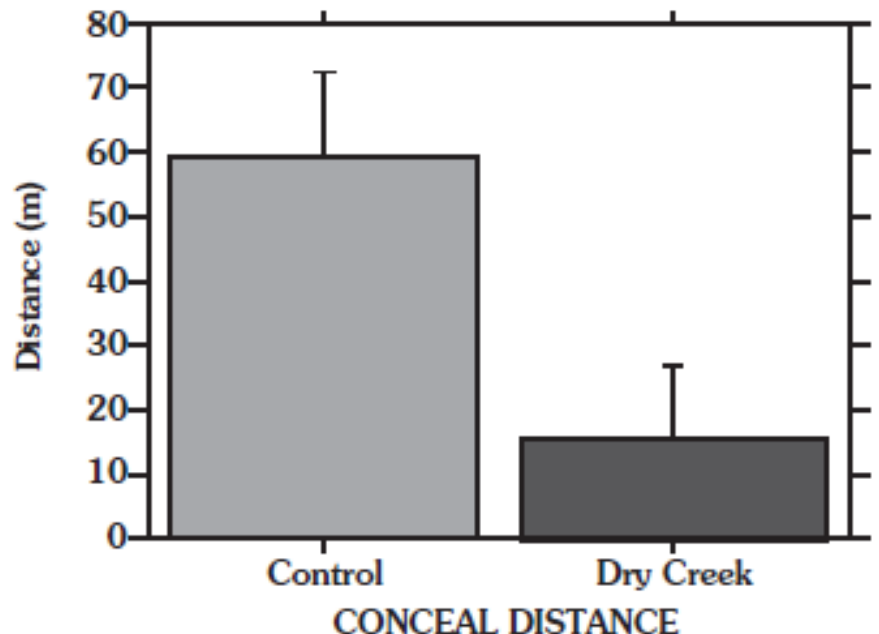

Human Attitudes towards Prairie Dogs, Dogs, and People

Our surveys ( $n=43$ of which 41 people were dog owners) showed that people at Dry Creek believed that there were too many unruly people $(29.4 \%)$ rather than too many unruly dogs $(8.8 \%)$. The only two nondog owners surveyed agreed. More than half (51.2\%) reported they had seen prairie dogs disturbed by dogs, but only occasionally rather than regularly ( $88.9 \%$ of the people reporting seeing disturbance). Seventeen percent reported they had seen people occasionally disturb prairie dogs. Sixteen percent 
reported that their dog did occasionally disturb prairie dogs, and $50 \%$ of these people reported that they tried to stop their own dog from disturbing prairie dogs, whereas $26.8 \%$ said they tried to stop other's dogs from disturbing prairie dogs. Twenty-one percent said they tried to stop people from disturbing prairie dogs. The biggest problems that people identified at Dry Creek included too many people (11.8\%), too many unruly dogs (8.8\%), too many unruly people (29.4\%), and too much dog poop (20.6\%). No respondents reported that there were too many dogs. All respondents reported that dogs should not be banned from Dry Creek and 58.3\% (all dog owners) said that prairie dogs should not be protected even if dogs were a problem. All respondents said that it would lessen their own and their dog's experience of the outdoors if their dog had to be leashed (see also Bekoff and Meaney 1997).

Figure 3. Mean concealment times (and 95\% confidence intervals) for prairie dogs' responses to humans at the control site ("undisturbed") and at Dry Creek ("disturbed").

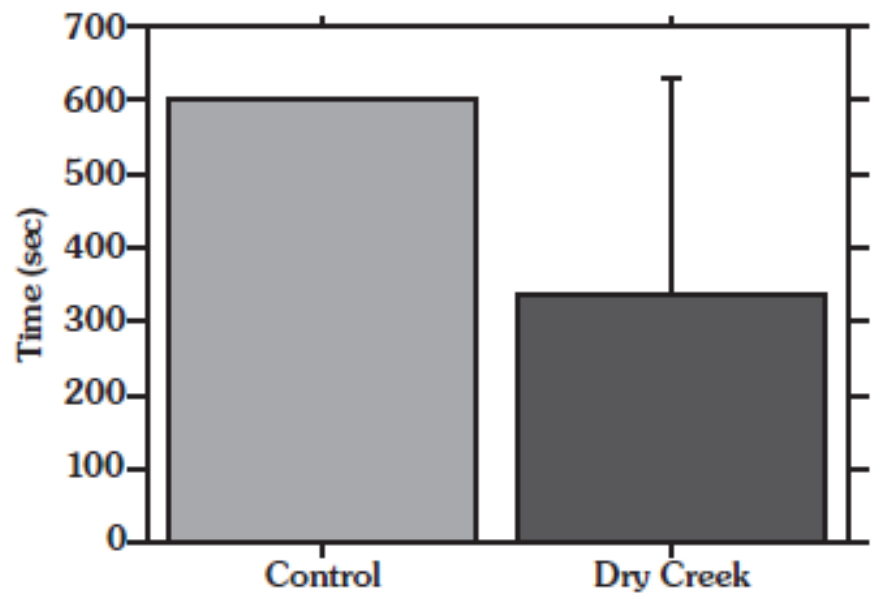

CONCEAL TIME

\section{DISCUSSION}

\section{Dogs and Prairie Dogs}

There is a lot of interest in prairie dogs and how they are influenced by the presence of, and intrusions by, human and non-human animals. People around Boulder and elsewhere are divided on central issues concerning the impact on wildlife of humans and their companion animals. Our main objective was to develop a basic scientific understanding of the nature of dog-prairie dog interactions, an issue that has high visibility in Boulder because some people want dogs to run free even if they disturb prairie dogs, whereas others want prairie dogs to be protected and dogs to be restrained or taken elsewhere for recreation. It would be unfortunate for all involved if these issues became contentious and could not be discussed openly using available data. Trying to manage dog or prairie dog populations before relevant data are collected would be premature and likely not solve the issues at hand.

Dogs at Dry Creek went off trail more often and further than dogs at other locations in Boulder (for comparative data see Bekoff and Meaney 1997), probably because of the presence of prairie dogs at Dry Creek and not at other locations.

Disturbed prairie dogs were less wary and more habituated to the presence of humans than undisturbed animals, a finding that is consistent with what has been reported for other locations (Adams et al. 1987, Farrar et al. 1998). Prairie dogs disturbed by dogs were more vigilant and played less than undisturbed 
individuals. This may indicate a higher level of stress among disturbed individuals. While prairie dogs will try to challenge small predators such as snakes (Halpin, 1983), they do not directly confront dogs. Similar to prairie dogs hunted by humans (Vosburgh and Irby 1998), prairie dogs spent more time alert, nervously scanning for intruders.

Despite the fact that prairie dogs are disturbed by dogs, neither we nor anyone else seems to know if dogs have any negative effects on the health, mortality, or reproductive success of these rodents. Little also is known about the effects of non-lethal intrusions by humans on the health, mortality, or reproductive success of prairie dogs. If dogs (or humans) have negative effects, this and other similar colonies may be in danger. Prairie dogs also have keen senses of smell but we do not know what effects dog odors and waste products have on them. However, prairie dogs are sensitive to the odors of such natural predators as black-footed ferrets (Andelt and Beck 1998). It also is not clear if plague can be introduced from one colony to another by dogs traveling from one prairie dog colony to another. Currently, it is not known if City of Boulder officials will pursue these important lines of research.

Dogs clearly influence the behavior of prairie dogs at Dry Creek. Prairie dogs are favored prey of many wild predators, but none were known to be killed by dogs. While it is known that human traffic can lead to a decrease in the presence of some predatory birds (Berry, Bock, and Haire 1998, and references therein), it is not known if dog traffic deters natural predators.

\section{Prairie Dogs and People}

People tried to stop dogs from harassing prairie dogs only $25 \%$ of the time. Our survey showed that fiftyeight percent of people surveyed at Dry Creek (all dog owners) did not believe that prairie dogs should be protected even if dogs are a problem. The only two non-dog owners polled agreed. Certainly, dog owners and people could play more active roles in preventing dogs from harassing prairie dogs. Increased human responsibility would probably go a long way towards reducing existing conflict among people wanting to protect prairie dogs and those who do not.

In the present study and our previous research, we found that people, dog owners and non-dog owners alike, agreed that the biggest problem at recreational sites in Boulder was too many unruly people (those who do not control their dogs or lure their dogs off trail, and those who leave the trails themselves), not too many unruly dogs.

\section{Developing Proactive Strategies}

There is still much to learn about the complex interactions among humans and non-humans so that all can benefit from the good fortune of having nearby recreational and wildlife areas. This information is essential for the development of proactive strategies. Can all participants be accommodated? Can a restricted area be both recreational and preservational? Should wild animals be given more consideration and protection than domesticated animals? Can animals and land be protected from interminable destruction and development? Even experts disagree about facts and possible solutions. There are no quick answers to these extremely difficult questions.

The data collected in the present study should be important for educating the public that there are indeed areas of conflict that demand careful and informed resolution, which will in turn facilitate dialogue between parties. Our data have been circulated among Boulder city officials and people using Dry Creek for recreation. Currently (June 1999), there is a plan to fence off the prairie dogs at Dry Creek to protect them from dogs. While this plan was developed before our data were available, this seems a reasonable temporary management plan until more information is available concerning the effects of dogs on the health and reproductive behavior of prairie dogs. 
In the future, our data should be useful for maximizing the well-being of prairie dogs (and other wildlife), dogs, and humans in Boulder and elsewhere by identifying specific areas of potential conflict [such as the friction between people who want to protect prairie dogs (and other wildlife) and those who want dogs to run free regardless of their impact on prairie dogs]. Our data should also be useful for developing proactive strategies of management that are grounded by empirical data.

\section{ACKNOWLEDGMENTS}

We thank Mimi Lam, Taryn Flowers, Delia Bellina, Katie Chell, Lindsay Dosch, Eliza Eubank, Jennifer Garcia, Susie Graham, Nathan Inouye, Jordan McClelland, Brian Schopfer, Jessica Taylor, John Reed, and Kyle Ashton for help with this study. Kyle Ashton, Stan Godlovitch, Carron Meaney, Bill Merkle, John Reed, Penny Bernstein, and an anonymous reviewer provided comments on a previous draft of this paper.

\section{REFERENCES}

Adams, R. A., Lengas, B. J. and Bekoff, M. 1987. Variations in avoidance responses to humans by Blacktailed prairie dogs (Cynomys ludovicianus). Journal of Mammalogy 68: 686-689.

Altmann, J. 1974. Observational study of behaviour: Sampling methods. Behaviour 49: 227-267.

Andelt, W. F. and Beck, T. D. I. 1998. Effect of black-footed ferret odors on behavior and reproduction of prairie dogs. Southwestern Naturalist 43: 344-351.

Bekoff, M. and Meaney, C. A. 1997. Interactions among dogs, people, and the environment in Boulder, Colorado: A case study. Anthrozoös 10: 23-31.

Berry, M. E., Bock, C. E. and Haire, S. L. 1998. Abundance of diurnal raptors on open space grasslands in an urbanized landscape. Condor 100: 601-608.

Bruning, J. L. and Kintz, B. L. 1977. Computational Handbook of Statistics. Glenview, Illinois: Scott, Foresman and Company.

Davitt, K., Grandi, R., Neasel, C. and Skeele, T. ed. 1996. Conserving Prairie Dog Ecosystems on the Northern Plains. Predator Project, Bozeman, Montana.

Dold, C. 1998. Making room for prairie dogs. Smithsonian Magazine 28: 60-68.

Farrar, J. P., Coleman, K. L., Bekoff, M. and Stone, E. 1998. Translocation effects on the behavior of black-tailed prairie dogs (Cynomys ludovicianus). Anthrozoös 11: 164-167.

Halpin, Z. T. 1983. Naturally occurring encounters between black-tailed prairie dogs (Cynomys ludovicianus) and snakes. American Midland Naturalist 109: 50-54.

Hoogland, J. L. 1995. The Black-Tailed Prairie Dog: Social Life of a Burrowing Mammal. Chicago, Illinois: University of Chicago Press.

Knight, R. L. and Gutzwiller, K. J. ed. 1995. Wildlife and Recreation: Coexistence Through Management and Research. Washington, D.C.: Island Press.

Long, M. E. 1998. The vanishing prairie dog. National Geographic 193: 116-131.

Miller, B. J., Reading, R. P. and Forrest, S. 1996. Prairie Night: Blackfooted Ferret and Recovery of an Endangered Species. Washington, D. C.: Smithsonian Institution Press.

Miller, C. K. 1994. Environmental impacts of passive recreational trails in riparian areas. Proceedings of the 6th Annual Colorado Riparian Association Conference, 12 pages.

Reading, R. P., Miller, B. J. and Kellert, S. R. 1999. Values and attitudes toward prairie dogs. Anthrozoös 12: 43-52.

Stapp, P. 1998. A reevaluation of the role of prairie dogs in Great Plains grasslands. Conservation Biology 12: 1253-1259.

Vosburgh, T. C. and Irby, L. R. 1998. Effects of recreational shooting on prairie dog colonies. Journal of Wildlife Management 62: 363-372. 